\title{
Marginal mandibular branch of the facial nerve: An anatomical study
}

\author{
Arvinder Pal Singh Batra, Anupama Mahajan, Karunesh Gupta ${ }^{1}$ \\ Department of Anatomy, SGRD Institute of Medical Sciences and Research, ${ }^{1}$ Chakitsa Hospital, Amritsar, Punjab, India
}

Address for correspondence: Dr. Arvinder Pal Singh Batra, Department of Anatomy, SGRD Institute of Medical Sciences and Research, Amritsar-143001, Punjab, India. E-mail: apsbatra@indiatimes.com

\section{ABSTRACT}

Smile is one of the most natural and important expressions of human emotion. Man uses his lips mainly to register his emotions. Thus, the slightest asymmetry or weakness around the lips and mouth may transform this pleasant expression into embarrassment and distortion. The circumoral musculature, the major part of which is supplied by the marginal mandibular branch of the facial nerve, is the main factor in this expression. Therefore, an injury to this nerve during a surgical procedure can distort the expression of the smile as well as other facial expressions. This nerve often gets injured by surgeons in operative procedures in the submandibular region, like excision of the submandibular gland due to lack of accurate knowledge of variations in the course, branches and relations. In the present study, 50 facial halves were dissected to study the origin, entire course, termination, branches, muscles supplied by it, its anastomoses with other branches of facial nerve on the same as well as on the opposite side and its relations with the surrounding structures. The marginal mandibular branch of the facial nerve was found superficial to the facial artery and (anterior) facial vein in all the cases (100\%). Thus the facial artery can be used as an important landmark in locating the marginal mandibular nerve during surgical procedures. Such a study can help in planning precise and accurate incisions and in preventing the unrecognized severance of this nerve during surgical procedures.

\section{KEY WORDS}

Facial nerve; marginal mandibular nerve; smile distortion

\section{INTRODUCTION}

Il the muscles of facial expression derive their nerve supply from the facial nerve. ${ }^{[1]}$ Of the five major branches of the facial nerve, the marginal mandibular branch of the facial nerve supplies muscles of the lower lip. The most frequent cause of paralysis of this nerve is iatrogenic injury during operations in the mandibular or parotid regions..$^{[2,3]}$ The marginal mandibular nerve runs forward below the angle of the mandible under the platysma, at first superficial to the upper part of the digastric triangle and then turning up and forward across the body of the mandible to supply muscles of the lower lip. A person with injury to the marginal mandibular branch of the facial nerve presents a very conspicuous deformity on opening the mouth, smiling or grimacing. It is due to paralysis of muscles of the lower lip of that side. The correction of resultant deformity may require complex surgical procedures like transfer of anterior belly of digastric muscle or extensor digitorum brevis. ${ }^{[4]}$ Therefore, a through knowledge of major variations of this nerve is essential to prevent its 
damage and resultant residual embarrassing paralysis.

\section{MATERIAL AND METHODS}

The present study was conducted at the Department of Anatomy, Sri Guru Ram Das Institute of Medical Sciences and Research, Amritsar. Fifty facial halves were taken from adult embalmed cadavers irrespective of age and sex. A submandibular incision was given, extending posteroinferiorly from the tragus of the ear up to the symphysis menti, running below and parallel to the lower border of the mandible. After reflection of skin flap and fascia, the platysma muscle was separated from the underlying structures by blunt dissection. Facial artery and the (anterior) facial vein were identified near the antero-inferior angle of the masseter muscle. The nerve was then traced from the vessel posteriorly up to the antero-inferior border of the parotid gland and anteriorly to its termination near the midline where it merges with fibres of muscles of the lower lip. As the terminal branches were very fine and difficult to trace, these branches were dissected as distally as possible with the help of a $4 \mathrm{x}$ magnifying loop to trace the facial nerves. The mode of origin, termination, course and number of branches of the marginal mandibular branch of the facial nerve were noted. Its relationship with the angle and inferior border of the mandible, with facial artery, with (anterior) facial vein and other surrounding structures was recorded. Its peripheral anastomoses with other branches of the facial nerve of the same and the opposite side were observed.

\section{RESULTS}

Table 1 presents the number of branches of the marginal mandibular branch of the facial nerve at various levels. Of the 50 cadavers studied for marginal mandibular branch of facial nerve, $44(88 \%)$ had a single branch at origin, 46 (92\%) had a single branch during course and $42(84 \%)$ of the cadavers had more than two branches at termination. This showed that branches were more at termination than the origin and course of the nerve.

Table 2 presents the relation of the marginal mandibular branch of the facial nerve with the surrounding structures. Of the 50 cadavers studied, marginal mandibular branch of facial nerve is superficial to facial artery and facial vein in $100 \%$ of the cases.

Table 3 shows anastomoses of the marginal mandibular branch of the facial nerve with other nerves. Of the 50 cadavers studied for marginal mandibular branch of the facial nerve, it has anastomosis with the buccal branch of the facial nerve of the same side and the mental nerve.

\section{DISCUSSION}

Based on dissection of 50 facial halves, the marginal mandibular branch of the facial nerve was found to be emerging from the inferior border of the parotid gland in $88 \%$ of the cases [Figure 1]. It terminated most frequently $(88 \%)$ in small multiple twigs, which merged with the fibres of depressor anguli oris, depressor labi inferioris and mentalis muscles. The marginal mandibular branch of the facial nerve was a single branch in $32 \%$ of the cases, and in $68 \%$ of the cases this nerve consisted of two or more branches. ${ }^{[5]}$ In a second study, it was one branch in $28 \%$ of the cases, two branches in $52 \%$ of the cases, three in $18 \%$ and four in $2 \%$ of the cases. ${ }^{[6]}$ In the present study, it was found that, at exit, the marginal mandibular branch of the facial nerve had single branch in $88 \%$ cases [Figure 2] and two branches in $12 \%$ of cases. None of the specimens showed more than two branches at exit or during the course; however in $84 \%$ cases, there were more than two branches [Figure 3] at termination [Table 1].

The relation of the marginal mandibular branch of the facial nerve with the inferior border of the mandible is extremely important surgically. The marginal mandibular branch of the facial nerve is always above the inferior border of the mandible while anterior to the facial artery. The position of this branch is variable when posterior to the facial artery; it is above the inferior border of the mandible in $81 \%$ and below the inferior border of the mandible in $19 \%$ of the cases. ${ }^{[7]}$ In the present study, the

\begin{tabular}{cccc}
$\begin{array}{c}\text { Table 1: Number of branches of the marginal mandibular } \\
\text { branch of the facial nerve at various levels }\end{array}$ \\
$\begin{array}{lccc}\text { No. of } \\
\text { branches }\end{array}$ & $\begin{array}{c}\text { No. of } \\
\text { specimens }\end{array}$ & Percentage \\
\hline At the exit & Single & 44 & 88.0 \\
& Two & 6 & 12.0 \\
More than two & -- & -- \\
During the course & Single & 46 & 92.0 \\
& Two & 4 & 8.0 \\
& More than two & -- & -- \\
Near termination & Single & 2 & 4.0 \\
& Two & 6 & 12.0 \\
& More than two & 42 & 84.0 \\
\hline
\end{tabular}




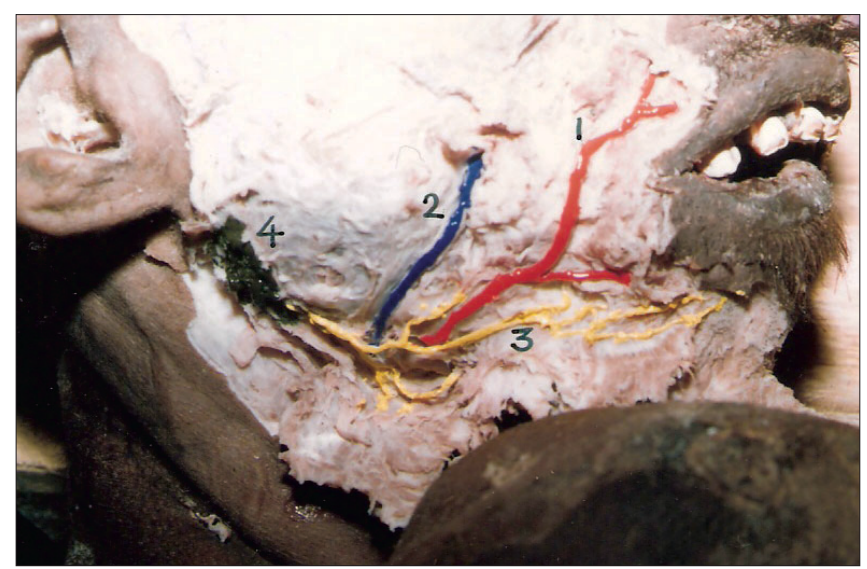

Figure 1: Marginal mandibular branch of the facial nerve arising from the inferior border of the parotid gland. (1) Facial artery, (2) Facial vein,

(3) Marginal mandibular branch of the facial nerve, (4) Parotid gland

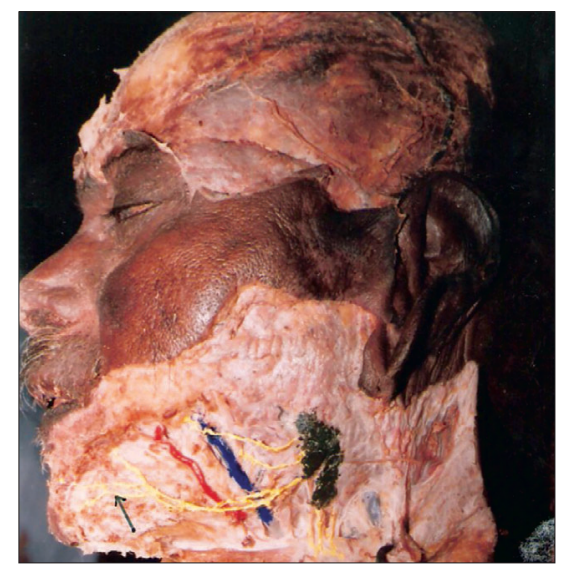

Figure 3: Three branches of the marginal mandibular nerve near its termination

marginal mandibular branch of the facial nerve was always above the inferior border of the mandible while anterior to the facial artery, along the inferior border in $52 \%$ and below the inferior border in $32 \%$ of the cases when it was posterior to the artery. These findings of the marginal mandibular branch of the facial nerve running along the lower border of the mandible have been described in the literature. ${ }^{[8,9]}$

The distance of the marginal mandibular branch of the facial nerve from the inferior border of the mandible has been studied by a number of workers, ${ }^{[10,11]}$ and varies from 1.4 to $1.75 \mathrm{~cm}$. In the present study, the distance of the nerve from the inferior border of the mandible varied from 0.9 to $1.4 \mathrm{~cm}$, with an average distance of $1.2 \mathrm{~cm}$, which is in accordance with the observations made by other workers. The marginal mandibular branch of the facial nerve must be looked for in all operative

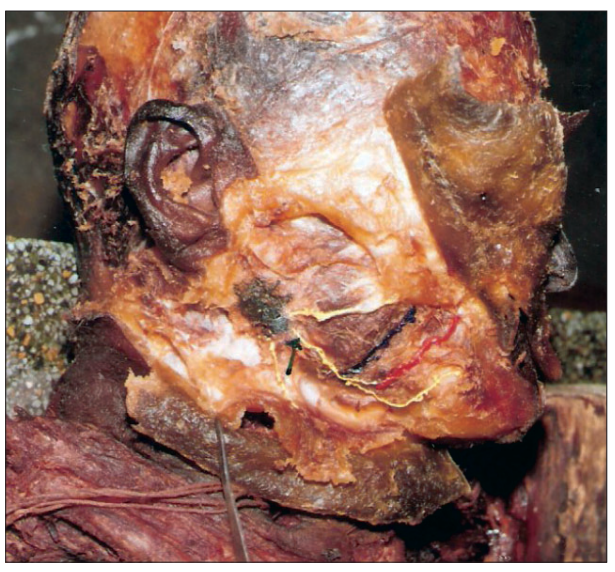

Figure 2: Single branch of the marginal mandibular nerve at exit

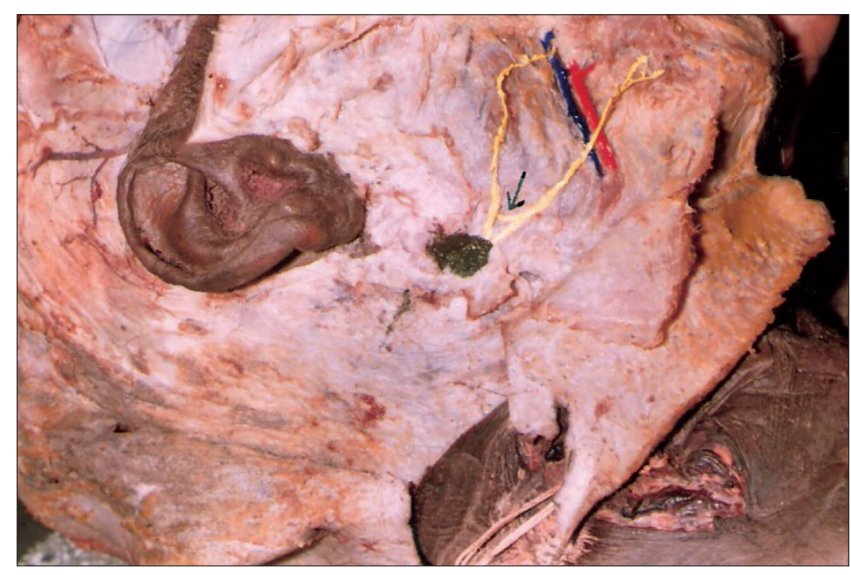

Figure 4: Anastomoses of the marginal mandibular branch of the facial nerve with the buccal branch of the facial nerve on the same side near their exit from the parotid gland

procedure near the angle of the mandible to a distance of $1.5 \mathrm{~cm}$ below the lower margin of the mandible. ${ }^{[1]}$ Therefore, in order to avoid damage to the nerve in the submandibular region, the incision should be made 1.5 $\mathrm{cm}$ or more below the lower border of the mandible.

The marginal mandibular branch of the facial nerve makes a curve below and in front of the angle, about one finger breadth below the mandible. ${ }^{[12]}$ By giving an incision of two fingers breadth below and parallel to the angle of the mandible, the marginal mandibular branch of the facial nerve can be isolated in the upper flap. ${ }^{[13]}$ In the present study, the nerve was found lying along the angle of the mandible in $52 \%$, below in $32 \%$ and above in $16 \%$ of the cases. When it was below the angle, the distance varied from 1.1 to $1.6 \mathrm{~cm}$, with an average of $1.5 \mathrm{~cm}$ from the angle of the mandible. This is in accordance with other studies. ${ }^{[12,13]}$ Therefore, a submandibular incision can be 
safely given about $2 \mathrm{~cm}$ below and parallel to the angle of the mandible [Table 2].

In the present study, the marginal mandibular branch of the facial nerve was seen superficial to the facial artery and anterior facial vein in $100 \%$ of the cases, which is in accordance with the observations made by others. ${ }^{\mid 12,14,15]}$ Thus, facial artery can be used as an important landmark in the course of the nerve. The pulsations of the facial artery can be readily palpated by the surgeon at the anteroinferior angle of the masseter muscle. This landmark is an important guide in locating the marginal mandibular nerve during surgical procedures [Table 3].

The anastomoses brtween the marginal mandibular branch of the facial nerve with other branches of the facial nerve of the same or opposite side is rare; this explains as to why injury to this nerve usually causes permanent paralysis of the muscle of the lower lip of that side. In the present study, the anastomosis of the marginal mandibular branch of the facial nerve with the buccal branch of the facial nerve was observed in only $12 \%$ of the cases [Figure 4 ]. In the remaining $88 \%$ of the cases, there was no anastomosis of this nerve with any other branch of the facial nerve. The marginal mandibular branch of the facial nerve has no anastomosis peripherally with any other ramus of the facial nerve. For this reason, permanent paresis of the homolateral half of the lower lip will inevitably follow the transection of the marginal mandibular branch of the facial nerve. ${ }^{[16]}$ The marginal mandibular branch of the facial nerve anastomoses with the buccal branch in $6.3 \%$ of the cases only ${ }^{[17]}$ and between the mandibular and buccal rami in $5 \%$ of the cases. ${ }^{[7]}$ Ramus mandibularis connects with the buccal branch in approximately $15 \%$ of the cases. ${ }^{[18]}$ The present study corresponds with the findings of other workers. ${ }^{[17,18]}$ Anastomosis of the marginal mandibular branch of the facial nerve with the mental nerve was observed in $28 \%$ of the cases [Table 3].

\section{CONCLUSION}

Based on the dissection of 50 facial halves, the marginal mandibular branch of the facial nerve was found emerging from the inferior border of the parotid gland in $88 \%$ of the cases. Peripheral anastomoses between the marginal mandibular branch of the facial nerve and the buccal branch of the facial nerve was found in $12 \%$ of the cases only. Near its termination, it frequently anastomosed with the mental nerve $(28 \%)$. Because of the poor anastomosis of the marginal mandibular branch of the facial nerve with other facial rami in its peripheral distribution, injury to this nerve causes a permanent

Table 2: Relationship of the marginal mandibular branch of the facial nerve with surrounding structures

\begin{tabular}{|c|c|c|c|}
\hline Structure & Relations & No. of specimens & Percentage \\
\hline \multirow{3}{*}{$\begin{array}{l}\text { With inferior border of the mandible while anterior } \\
\text { to the facial artery }\end{array}$} & Above the inferior border & 50 & 100.0 \\
\hline & Below the inferior border & - & - \\
\hline & Along the inferior border & - & - \\
\hline \multirow{3}{*}{$\begin{array}{l}\text { With inferior border of the mandible while } \\
\text { posterior to the facial artery }\end{array}$} & Above the inferior border & 8 & 16.0 \\
\hline & Below the inferior border & 16 & 32.0 \\
\hline & Along the inferior border & 26 & 52.0 \\
\hline \multirow[t]{3}{*}{ With the angle of the mandible } & Above the angle of the mandible & 8 & 16.0 \\
\hline & Below the angle of the mandible & 16 & 32.0 \\
\hline & Along the angle of the mandible & 26 & 52.0 \\
\hline \multirow[t]{2}{*}{ With the facial artery and its branches } & $\begin{array}{l}\text { Superficial to the facial artery and its } \\
\text { branches }\end{array}$ & 50 & 100.0 \\
\hline & Deep to the facial artery and its branches & - & - \\
\hline \multirow[t]{2}{*}{ With (anterior) the facial vein } & Superficial to the (anterior) facial vein & 50 & 100.0 \\
\hline & Deep to the (anterior) facial vein & - & - \\
\hline
\end{tabular}

Table 3: Anastomoses of the marginal mandibular branch of the facial nerve with other nerves

\begin{tabular}{lcc} 
& No. of specimens & Percentage \\
\hline Anastomosis with the buccal branch of the facial nerve of the same side & 6 & 12.0 \\
Anastomosis with the buccal branch of the facial nerve on the opposite side & - & - \\
Anastomosis with any branch of the facial nerve other than the buccal branch (either side) & - \\
Anastomosis with the mental nerve & 14 & 28.0 \\
\hline
\end{tabular}


paralysis of the musculature supplied.

In a majority of the dissections (52\%), the marginal mandibular branch of the facial nerve was found running along the angle and inferior border of the mandible. It was observed below the inferior border of the mandible in $32 \%$ of the cases. When below the angle and body of the mandible, its maximum distance was found to be 1.6 and $1.4 \mathrm{~cm}$, respectively. Therefore, in order to avoid damage to the marginal mandibular branch of the facial nerve, the submandibular incision should be planned $1.6 \mathrm{~cm}$ or more below the lower border and angle of the mandible. The marginal mandibular branch of the facial nerve was found superficial to the facial artery and (anterior) facial vein in all the cases $(100 \%)$. Thus, the facial artery can be used as an important landmark in locating the marginal mandibular nerve during surgical procedures.

\section{REFERENCES}

1. Egasse D. Facial nerve: Particular aspects of the cervicofacial anatomy. Ann Dermatol Venereol 2001; 128:59-62.

2. O'Brien CJ. Facial nerve localization in parotid surgery. ANZ J Surg 2002; 72:370.

3. Toure S, Vacher C, Bertrand JC. Anatomy of the marginal mandibular branch of facial nerve. Rev Stomatol Chir Maxillofac 2004; 105:149-52.

4. Tulley P, Webb A, Chana JS, Tas ST, Hudson D, Grobbelaar AO, et al. Paralysis of the marginal mandibular branch of the facial nerve: Treatment options. Br J Plast Surg 2000; 53:378-85.

5. Wang TM, Lin CL, Kuo KJ, Shih C. Surgical anatomy of the mandibular ramus of the facial nerve in Chinese adults. Acta Anat (Basel) 1991; 142:126-31.
6. Kim DI, Nam SH, Nam YS, Lee KS, Chung RH, Han SH. The marginal mandibular branch of the facial nerve in Koreans. Clin Anat 2009; 22:207-14.

7. Dingman RO, Grabb WC. Surgical anatomy of the mandibular ramus of the facial nerve based on the dissection of 100 facial halves. Plast Reconstr Surg Transplant Bull 1962; 29:266-72.

8. Spaltehoz W. Hand Atlas of Human Anatomy Vol 3. Philadelphia: J. B. Lippincott Company; 1903. p. 701-2.

9. Jackson IT, Sommerlad BC. Recent advances in plast Surg Vol 3. New York: Churchill Livingstone; 1985. p.175.

10. Rodel R, Lang J. Peripheral branches of the facial nerve in the cheek and chin area: Anatomy and clinical consequences. HNO 1996; 44:572-6.

11. Converse JM. Head and Neck Surgery In: Plastic and Reconstructive Surgery Second Edition, Vol 5. Philadelphia, Landon, Toronto: WB Saunders and Company; 1979. p. 112

12. Charles R, Rodney S. Rob Charles Operative surgery. London: Butterworths; 1983. p. 524-5.

13. Strelzow VV, Strelzow AG. Osteosynthesis of mandibular fractures in the angle region. Arch Otolaryngol 1983; 109:403-6.

14. Barron JN, Saad MN (Eds). Manual of operative Plastict and Reconstructve Surgery Vol 1. Edinburgh, United Kingdom: Churchill Livingstone; 1980. p. 437.

15. Stark RB. Secondary surgery of the lips. Plast Surg of the Head and Neck Vol 2. New York: Churchill Livingstone; 1987. p. 738 810, 822.

16. Martin $\mathrm{H}$. The operative removal of tumors of the parotid gland. Surgery 1952; 31:670-682.

17. Davis RA, Barry JA, Johan MS, Leroy EK. Surgical anatomy of the facial nerve and parotid gland based upon the study of 350 cervicofacial halves. Surg Gynecol Obstet 1956; 102:385-412.

18. Baker DC, Conley J. Avoiding facial nerve injuries in rytidectomy: Anatomical variations and pitfalls. Plast Reconstr Surg 1979; 64:781-95

Source of Support: Nil, Conflict of Interest: None declared. 